\title{
Alcohol dependence in gastroenterology outpatient on a public hospital
}

\author{
Mariana de Andrade PRANKE and Gabriela Perdomo CORAL
}

Received 19/4/2017 Accepted 29/6/2017

\begin{abstract}
Background - Alcoholism and alcoholic liver disease are both considered worldwide health problems. Objective - The prevalence of alcohol dependence, the associated risk factors and the concordance between the prevalence found and the data collected during the medical visit were evaluated. Methods - A prospective study evaluating gastroenterology outpatients at a public tertiary hospital was conducted. Two specific questionnaires to assess alcohol dependence were applied: Cut down, Annoyed by criticism, Guilty, Eye-opener (CAGE) and The Alcohol Use Disorder Identification Test (AUDIT). Data on comorbidities, clinical diagnosis and assessment of alcohol consumption by the attending physician were collected through medical records. Results - One hundred and seventy eight patients were interviewed, of which $119(66.9 \%)$ were women and 59 (33.1\%) were men, with mean age of 57 years. Thirty-three $(18.5 \%)$ of the 178 patients were considered alcohol-dependent by the CAGE questionnaire. Thirteen $(7.3 \%)$ patients scored 8 points or more on the AUDIT questionnaire. The agreement (kappa) between these questionnaires was $0.37(P<0.001)$. The most consumed drink was beer. The median daily consumption of dependent patients was $64 \mathrm{~g}$. None of the patients were undergoing treatment in a specific treatment center, and 14/33 (42.4\%) patients considered themselves alcoholics. Only in 17/33 (51.5\%) there was information about alcoholism in their respective medical records. In the bivariate analysis, male gender $(P<0.001)$, onset of alcohol consumption before the age of $15(P=0.003)$, daily alcohol consumption in the last 12 months $(P<0.001)$ and smoking $(P<0.001)$ were identified as risk factors. After multivariate analysis, only male gender $(P=0.009)$ and smoking $(P=0.001)$ were associated with alcoholism. Conclusion - The present study demonstrated a high prevalence of alcohol dependence in the gastroenterology outpatient clinic, being predominantly associated with male gender and smoking. It is worth noting that approximately half of the dependents were not identified as such in the medical appointment, evidencing the importance of the diagnostic approach in the alcoholic outpatient.
\end{abstract}

HEADINGS - Alcohol drinking. Ambulatory care. Comorbidity. Diagnosis. Liver diseases. Prospective studies.

\section{INTRODUCTION}

Excessive alcohol consumption is one of the main causes of morbidity and mortality in the world, with alcoholic liver disease being the main cause of such outcomes ${ }^{(8,30,35,38)}$. The excessive intake of alcohol is one of the five major risk factors for death or disability worldwide ${ }^{(21)}$, resulting in 2.5 million deaths and 69.4 million incapacitations per year ${ }^{(34)}$. In Brazil, liver disease was the eighth leading cause of death and alcoholic cirrhosis was the second most frequent cause of hospitalization for liver disease from 2001 to $2010^{(26)}$.

The World Health Organization (WHO) recommends that the maximum daily alcohol intake should be $20 \mathrm{~g}$ for women and $40 \mathrm{~g}$ for men, provided there are no restrictions, such as pregnancy or other risk factors for liver disease ${ }^{(40)}$. Hepatic steatosis is present in approximately $90 \%$ of individuals who consume $60 \mathrm{~g}$ or more of alcohol daily, and the continuous use of $40 \mathrm{~g} /$ day is associated with a risk of progression to fibrosis and cirrhosis in approximately $37 \%$ of individuals ${ }^{(13,33)}$.

Recently, there has been an increase in alcohol consumption worldwide. It is believed that in Brazil this progression is due in part to its low cost, with alcohol being easily accessible to all social classes, though studies evaluating the prevalence of alcohol consumption in our country are sparse. Brazilian studies that evaluated population samples (home interviews) found prevalence ranging between $2.5 \%$ and $20.2 \%{ }^{(1,2,10,15,19,25,28)}$. In primary care, a study conducted in the city of Bebedouro/SP found that the prevalence of dependence was $9.8 \%{ }^{(37)}$. When evaluating 385 patients admitted into a general hospital in the city of Porto Alegre, the prevalence was $13 \%{ }^{(31)}$. Studies investigating the prevalence of alcohol abuse in outpatients of a gastroenterology ambulatory were not found. The risk factors usually associated with alcoholism are male gender $r^{(1,2,3,6,10,15,25)}$, the presence of history of alcoholism in relatives $^{(1,2)}$ and smoking ${ }^{(1,2,10,15,25,28)}$.

The aim of the present study was to determine the prevalence of alcohol dependence in a public gastroenterology hospital ambulatory, to match the prevalence found with the data collected in the medical records and to evaluate the comorbidities and risk factors associated with alcohol dependence.

\section{METHODS}

A prospective cross-sectional study was conducted to evaluate patients who had a medical appointment at the ambulatory of

Declared conflict of interest of all authors: none

Disclosure of funding: no funding received

Programa de Pós-Graduação em Medicina: Hepatologia, Universidade Federal de Ciências da Saúde de Porto Alegre, Porto Alegre, RS, Brasil.Study performed at: Irmandade da Santa Casa de Misericórdia de Porto Alegre. Porto Alegre, RS, Brazil.

Correspondence: Mariana de Andrade Pranke da Silva. Av. Nilópolis 250/211 - Bloco B - CEP 90460-050 - Petrópolis - Porto Alegre, RS, Brasil. Email: maripranke@gmail.com 
gastroenterology at the Irmandade Santa Casa de Misericórdia de Porto Alegre (ISCMPA) from December 2014 to September 2015. This study was approved by the Research Ethics Committee of ISCMPA under registry 884.319. The number of patients estimated to assess the prevalence of alcohol dependence was $156^{(20)}$. All patients over the age of 18 who signed the informed consent form (ICF) were included. The exclusion criteria of the study were hepatic encephalopathy, being inebriated at the time of the interview or having any other condition that made the answers unfeasible. After explaining the research and having the patients sign the ICF, the patients answered a general questionnaire about their sociodemographic profile, including the following questions: birth data, gender, grade of instruction, occupation, civil status, personal history of tobacco use, history of alcoholism in the family, alcohol intake in the last 12 months, frequency and amount of alcohol ingestion; each patient was also asked about whether he or she considered him/herself to be an alcoholic and whether he or she was undergoing treatment in a specialized center for alcohol dependence.

Two questionnaires with specific questions about alcoholism were applied, even for those patients who reported never having had a drink: 1) Cut down, Annoyed by criticism, Guilty, Eyeopener (CAGE) ${ }^{(23)}$ composed of four distinct questions. This test was considered positive when the results are greater than or equal to two points ${ }^{(27)}$; 2) The Alcohol Use Disorder Identification Test (AUDIT). This test was considered positive when results were greater than or equal to eight points. This questionnaire should be answered according to consumption in the last 12 months $^{(5)}$. The concordance between the tests was assessed by the kappa test.

Whole duration of the interview (after signing the ICF) was evaluated in minutes. Medical records were evaluated retrospectively by the assistant doctor in order to verify the medical condition of the patient, comorbidities and diagnosis of alcoholism.

The risk factors evaluated were: age, gender, occupation, history of alcoholism in the family, history of consumption (if they never drink, only tried or consume/consumed alcoholic beverages), age when patient consumed alcoholic beverages for the first time, daily use of alcohol in the last 12 months and history of tobacco use.

Continuous variables were expressed as mean (SD), and categorical variables as absolute frequencies and percentages. Mean values were compared between groups using Student's $t$-test, and percentages were compared using Pearson's chi-square test. Multivariate Poisson regression was used to control for potential confounders. A bivariate analysis must have resulted in $P$ value $<0.20$ in order to enter the variable into this multivariate model. Prevalence ratios (PR) with 95\% confidence intervals were used as effect measures. The level of significance was set at 5\% $(P \leq 0.05)$, and all analyses were performed using SPSS, version 22.0.

\section{RESULTS}

Two hundred and ten patients were invited to participate in the study. Thirty two $(15.2 \%)$ did not agree to participate in the study; of those, $16(50 \%)$ patients reported that they did not have time to participate, $9(28.1 \%)$ did not give a reason for not participating, $3(9.4 \%)$ did not want to talk about alcoholism and $4(12.5 \%)$ provided other reasons for not participating in the study. Of the 32 patients who refused to participate, 18 (56.2\%) did so before reading the ICF.
Thus, the sample analyzed was composed of 178 patients. Table 1 describes the characteristics of this sample. The mean age was 57 years (18-88). Out of the participants, $119(66.9 \%)$ were women and $59(33.1 \%)$ were men. With regard to schooling, 106 (59.6\%) had completed elementary school; only $15(8.5 \%)$ had technical or higher education. Regarding occupation, $60(33.7 \%)$ were employed at the time of the interview. Ninety-four $(52.8 \%)$ were married. Seventy-seven $(43.3 \%)$ were smokers. The length of interview was less than 15 minutes for $136(76.4 \%)$ participants.

Sixty $(41.4 \%)$ patients reported never having consumed alcoholic beverages; 28 (19.3\%) patients reported that they had only tried some alcoholic beverages but did not continue to consume, and $90(50.6 \%)$ patients actively drink alcohol or are alcoholics in abstinence.

TABLE 1. Characteristics of the sample studied at the gastroenterology outpatient clinic

\begin{tabular}{lc}
\hline Variables & $\mathrm{n}=178$ (\% of sample) \\
\hline Age (years) - medium \pm SD & $57 \pm 14$ \\
Gender & $119(66.9)$ \\
Female & $59(33.1)$ \\
Male & \\
Schooling & $9(5.1)$ \\
Analphabet & $106(59.6)$ \\
Fundamental teaching & $48(27.0)$ \\
Medium teaching & $15(8.4)$ \\
Technician or college & \\
Ocupation & $72(40.5)$ \\
Retired & $60(33.7)$ \\
Employee & $46(25.8)$ \\
Others & \\
Civil status & $94(52.8)$ \\
Married & $37(20.8)$ \\
Not married & $23(12.9)$ \\
Divorced & $24(13.5)$ \\
Widower & \\
Tabagism & $77(43.3)$ \\
Yes & $101(56.7)$ \\
No & \\
Interview time & $136(76.4)$ \\
Up until 15 minuts & $42(23.6)$ \\
Above 15 minuts & \\
\hline &
\end{tabular}

SD: standard deviation.

Considering all the patients interviewed, the most common comorbidities were: gastroesophageal reflux disease, peptic ulcer and chronic gastritis, which were present in approximately $60 \%$ of the cases. When only patients with alcohol dependence were considered, chronic liver diseases were the most frequent comorbidities, being present in approximately $61 \%$ of patients.

Thirty-three $(18.5 \%)$ patients were considered alcohol dependent by the CAGE questionnaire. The positive answers for each of the four questions were: 32 (question 1), 26 (question 2), 22 (question 3) and 13 (question 4). According to the AUDIT questionnaire, which assesses dependence in the last 12 months, 
$13 / 178(7.3 \%)$ patients were considered alcohol dependents. Tables 2 and 3 show the comparison between the CAGE and AUDIT questionnaires. There was a poor agreement between these questionnaires (kappa 0.37, $P<0.001$ ).

TABLE 2. CAGE questionary pontuation

\begin{tabular}{lc}
\hline Total Score & $\mathrm{n}=178(\%$ of sample $)$ \\
\hline 0 Points & $133(74.7)$ \\
1 Point & $12(6.7)$ \\
2 Points & $22(12.4)$ \\
3 Points & $7(3.9)$ \\
4 Points & $4(2.3)$ \\
Positives patients $\left(\mathrm{CAGE}_{2} 2\right)$ & $33(18.5)$
\end{tabular}

CAGE: cut down, annoyed by criticism, guilty, eye-opener

TABLE 3. AUDIT Questionary Pontuation

\begin{tabular}{lc}
\hline Total score & $\mathrm{n}=178(\%$ of sample) \\
\hline 0 a 7 points & $165(92.7)$ \\
8 a 15 points & $9(5.1)$ \\
16 a 19 points & $3(1.7)$ \\
20 a 40 points & $1(0.6)$ \\
Positives patients (audit $\geq 8)$ & $13(7.3)$
\end{tabular}

When questioned, none of the dependent patients reported undergoing specific treatment for substance abuse. Only 14/33 (42.4\%) considered themselves as alcoholics. Regarding the review of medical charts, alcohol use information was reported in $17 / 33$ $(51.5 \%)$, and in only $8 / 33(24.2 \%)$ medical records contained detailed data such as amount ingested and frequency of ingestion.

The median daily alcohol consumption of patients with alcohol

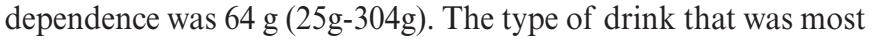
consumed among these patients was the beer.

In the bivariate analysis (Table 4), alcohol dependence was related to: male gender $(23,69.7 \%)$, patients who consume or used to consume alcoholic beverages $(33,18.5 \%)$, patients who started drinking alcoholic beverages before the age of $15(17,51.5 \%)$, patients who consumed alcoholic beverages in the last 12 months $(6,18.2 \%)$, smoking $(28,54.8 \%)$ and more than 15 minute for interview $(20,60.6 \%)$.

Table 5 shows the results of the multivariate Poisson regression analysis. Alcoholic patients were 2.52 times more likely to be male $(P=0.009)$. In addition, smokers were 4.81 times more likely to have a diagnosis of alcohol dependence when compared to nonsmokers $(P<0.001)$.

\section{DISCUSSION}

Alcohol abuse in Brazil is a public health problem. The World Health Organization (WHO) estimates that $7.29 \%$ of men and $1.41 \%$ of Brazilian women over 15 years of age are diagnosed with alcohol-related disorders ${ }^{(30)}$. In a National Survey conducted in 107 cities in Brazil (with population higher than 200,000), prevalence of alcohol dependence was $17.1 \%$ for males and $5.7 \%$ for females ${ }^{(18)}$. According to the literature, the prevalence of alcohol dependence ranges from $2.5 \%$ to $20.2 \% 0^{(1,10,15,18,19,25,28)}$. In the present study, the prevalence of alcohol dependence was $18.5 \%$
TABLE 4. Bivariate analysis for the identification of risk factors associated with alcohol dependence

\begin{tabular}{|c|c|c|c|}
\hline Variables & $\begin{array}{c}\text { Cage } \leq 2 \\
\mathrm{n}=145 \\
\mathrm{n}(\%)\end{array}$ & $\begin{array}{c}\text { Cage } \geq 2 \\
\mathrm{n}=33 \\
\mathrm{n}(\%)\end{array}$ & $P$ \\
\hline Age (years)* & $58 \pm 14$ & $55 \pm 14$ & 0.220 \\
\hline Gender $^{\mathrm{b}}$ & & & $<0.001$ \\
\hline Male & $36(24.8)$ & $23(69.7)$ & \\
\hline Female & $109(75.2)$ & $10(30.3)$ & \\
\hline Schooling $^{a}$ & & & 0.902 \\
\hline Analphabet & $8(5.5)$ & $1(3.1)$ & \\
\hline Fundamental teaching & $85(58.6)$ & $21(63.6)$ & \\
\hline Medium teaching & $40(27.6)$ & $8(24.2)$ & \\
\hline Technician or college & $12(8.3)$ & $3(9.1)$ & \\
\hline Ocupation $^{\mathrm{a}}$ & & & 0.398 \\
\hline Retired & $59(40.7)$ & $13(39 ., 4)$ & \\
\hline Employee & $46(31.7)$ & $14(42.4)$ & \\
\hline Others & $38(26.2)$ & $6(18.2)$ & \\
\hline History of consumption ${ }^{a}$ & & & $<0.001$ \\
\hline Never & $60(41.4)$ & $0(0.0)$ & \\
\hline Just tried & $28(19.3)$ & $0(0.0)$ & \\
\hline Consumed & $57(39.3)$ & $33(100)$ & \\
\hline $\begin{array}{l}\text { Age that consumed the first } \\
\text { time }^{\mathrm{a}}\end{array}$ & & & 0.003 \\
\hline Up to 15 years & $20(23.5)$ & $17(51.5)$ & \\
\hline 16 years and over & $65(76.5)$ & $16(48.5)$ & \\
\hline $\begin{array}{l}\text { Consumed daily alcoholic } \\
\text { beverage in the last } 12 \\
\text { months }\end{array}$ & $2(1.4)$ & $6(18.2)$ & $<0.001$ \\
\hline $\begin{array}{l}\text { Do you have any family } \\
\text { alcoholic }^{\mathrm{b}}\end{array}$ & $87(60.0)$ & $16(48.5)$ & 0.311 \\
\hline Tabagism ${ }^{a}$ & & & $<0.001$ \\
\hline Yes & $49(33.8)$ & $28(84.8)$ & \\
\hline No & $96(66.2)$ & $5(15.2)$ & \\
\hline
\end{tabular}

* Medium $\pm \mathrm{SD}(t$-test $) \mathrm{n}=178 .{ }^{\mathrm{a}}$ Qui-square of Pearson. ${ }^{\mathrm{b}}$ Continuity correction.

TABLE 5. Factors independently associated with alcoholism through the multivariate poisson regression model

\begin{tabular}{lcc}
\hline Variables & PR (CI 95\%) & $\boldsymbol{P}$ \\
\hline Gender & 1 & 0.009 \\
$\quad \begin{array}{l}\text { Female } \\
\text { Male }\end{array}$ & $2.52(1.25-5.05)$ & \\
Tabagism & 1 & $<0.001$ \\
$\quad$ No & $4.81(1.92-12.1)$ & \\
$\quad$ Yes & & \\
$\begin{array}{l}\text { Consumed daily alcoholic beverage } \\
\text { in the last 12 months }\end{array}$ & 1 & 0.398 \\
$\quad$ No & $1.34(0.68-2.67)$ & \\
$\quad$ Yes & & \\
\hline
\end{tabular}

PR: prevalence ratio. Confidence interval of $95 \%$. 
as assessed by the CAGE questionnaire, which evaluates alcohol consumption throughout life. The model used, the place where the study was performed and the characteristics of the sample are factors that may justify the wide range of prevalence found in the literature ${ }^{(1,10,15,19,25,28)}$. The present study found a higher prevalence than previous studies, which was probably related to the fact that the sample consisted of patients attending a gastroenterology outpatient clinic of a public care hospital, thus possibly having selected a sample with a greater possibility of dependence.

Similar to the current study, other studies also show a predominance of the female gender in the evaluated sample ${ }^{(1,15,28,31,37)}$; as well as a predominance of schooling level up to elementary school $^{(1,15,28,31,37)}$. The prevalence of smoking was high in the present sample $(43 \%)$, as already demonstrated in the literature ${ }^{(2,10,15,19,28,37)}$.

It is worth noting that in the present study, approximately $52 \%$ of patients who consume or have consumed alcohol were not identified as such in medical charts. In 1998, Rosa et al. showed very similar results. Only $51 \%$ of the alcoholic patients admitted into a university hospital were diagnosed as such by the assistant team ${ }^{(31)}$.

Medical consultation can and should be the time to diagnose alcohol abuse and dependence, regardless of the medical complaint that led the patient to the appointment. This diagnosis allows the patient to be advised regarding alcohol dependence or abuse and referred for specific treatment. In addition, it is estimated that the majority of alcohol-dependent individuals seek clinical services for the treatment of illnesses caused by alcoholism, to the detriment of treatment in specialized addiction services ${ }^{(36)}$.

Alcohol abuse and its dependence leads to psychological, social, occupational and family damage ${ }^{(4,39)}$, as well as clinical comorbidities such as: chronic pancreatitis, hepatic steatosis, alcoholic hepatitis, liver cirrhosis, gastritis, reflux esophagitis, heart disease, neurological diseases and neoplasia ${ }^{(14,16)}$. In addition, alcohol abuse is frequently associated with smoking and the use of other drugs, as well as with psychiatric comorbidities such as depression ${ }^{(16)}$. The excessive and persistent use of alcohol is associated with a worse evolution of chronic HCV hepatitis and a higher incidence of hepatocellular carcinoma in patients with liver cirrhosis ${ }^{(7)}$.

According to the literature ${ }^{(2,3,15,19,25,28,37)}$, studies show that there is a direct relationship between alcohol and tobacco ${ }^{(10)}$. In the present study, both male gender and smoking were risk factors associated with alcohol dependence, being in agreement with what is found in the literature ${ }^{(2,10,15,19,25,28,37)}$. On the other hand, the female gender was predominant in the present study. In this way, it is possible that the found prevalence of dependence may have been underestimated.

The present study clearly demonstrates an association between smoking and alcoholism, a fact already demonstrated in the literature ${ }^{(2,10,15,19,28,37)}$. The chemical dependence and the legal use of these two substances possibly justify this association. The study of Galduróz et al. (2005) showed that $46.2 \%$ of men and $36.3 \%$ of women consume or have consumed cigarettes throughout their lives ${ }^{(18)}$.
In the study by Álvarez (2007), a family history of alcoholism was present in $83.8 \%$ of the sample, evidencing the importance of family association in alcoholism ${ }^{(2)}$. Such association was not demonstrated in the present study.

The use of specific questionnaires to assess alcohol dependence is an important diagnostic tool. In addition to the questionnaires used in this study (CAGE and AUDIT), other questionnaires - such as The Rapid Alcohol Problems Screen (RAPS) ${ }^{(11,12)}$, Alcohol Use Disorders Identification Test (AUDIT-C) $)^{(9)}$, Brief Michigan Alcoholism Screening Test, The Mini International Neuropsychiatric Interview (MINI) ${ }^{(32)}$ and Composite International Diagnostic Interview (CIDI) ${ }^{(27,29)}$ - may be used to assess alcohol dependence.

AUDIT is a screening test for patients who have used alcohol in an abusive and harmful manner in the last 12 months. It is considered a valuable questionnaire to identify alcohol dependence ${ }^{(17)}$. It is composed of ten questions, of which the first eight refer to the use of alcohol in the last year, with the last two questions possibly indicating a previous problem ${ }^{(17)}$. The AUDIT was translated and validated in Brazil. In the study of validation, a sensitivity of $91.8 \%$ and specificity of $62.3 \%$ were demonstrated for the Brazilian population $^{(22,24)}$. In the present sample the AUDIT identified fewer alcoholics in relation to the CAGE; it is postulated that this happened due to the fact that some patients were in abstinence probably after the diagnosis of liver disease.

The CAGE questionnaire has questions regarding the patient's past or current consumption habits, allowing the identification of alcohol dependence even in patients who have stopped drinking. The CAGE questionnaire was validated in Brazil ${ }^{(23)}$, and the sensitivity and specificity found were $84.74 \%$ and $73.33 \%$, respectively ${ }^{(27)}$.

The CAGE questionnaire is easy and quick to apply, does not require extensive training and is capable of tracking addiction to alcoholic beverages ${ }^{(17)}$. On the other hand, the AUDIT questionnaire, which is more extensive, requires prior training in relation to the concept of alcoholic beverage dose. It should be emphasized that in the present study, the length of the interview, including the application of the three questionnaires, was usually less than 15 minutes.

\section{CONCLUSION}

The present study demonstrated that the prevalence of alcohol dependence in a gastroenterology outpatient clinic was $18.5 \%$, being related to male gender and smoking. It is worth noting that approximately half of the sample was not identified as alcohol dependent on their medical appointment, evidencing the importance of the diagnostic approach in outpatient clinics as well as in primary care.

\section{Authors' contributions}

Pranke MA: data collection, survey execution, writing of text, statistical analysis. Coral GP: correction of text, writing of text. 
Pranke MA, Coral GP. Dependência alcoólica em ambulatório de gastroenterologia de um hospital público. Arq Gastroenterol. 2017;54(4):338-43.

RESUMO - Contexto - O alcoolismo e a doença hepática alcoólica são considerados problemas de saúde de relevância mundial. Objetivo - Avaliar a prevalência de dependência alcoólica, os fatores de risco associados e a concordância entre a prevalência encontrada e os dados coletados na consulta médica. Métodos - Estudo prospectivo, avaliando pacientes de ambulatório de gastroenterologia de um hospital terciário, composto por um questionário geral e dois específicos para avaliar a dependência de álcool: Cut down, Annoyed by criticism, Guilty, Eye-openner (CAGE) e o Alcohol Use Disorder Identification Test (AUDIT). Dados sobre comorbidades, diagnóstico clínico e aferição sobre o consumo de álcool pelo médico assistente, foram coletados através de revisão de prontuário. Resultados - Foram entrevistados 178 pacientes, $119(66,9 \%)$ mulheres e 59 (33,1\%) homens com média de idade de 57 anos. Trinta e três $(18,5 \%)$ dos 178 pacientes foram considerados dependentes alcoólicos pelo questionário CAGE. Treze (7,3\%) pacientes fizeram oito ou mais pontos no questionário AUDIT. A concordância (kappa) entre os testes foi $0,37(P<0,001)$. A bebida mais consumida foi a cerveja. A mediana de consumo diário dos pacientes dependentes foi de $64 \mathrm{~g}$, nenhum destes estava em tratamento em centro específico, 14/33 $(42,4 \%)$ pacientes seconsideravam alcoolistas e em apenas 17/33 (51,5\%) havia registro no prontuário sobre alcoolismo. Na análise bivariada, gênero masculino $(P<0,001)$, início de consumo de álcool antes dos 15 anos $(P=0,003)$, consumo diário de bebida alcoólica nos últimos 12 meses $(P<0,001)$ e tabagismo $(P<0,001)$ foram identificados como fatores de risco. Após análise multivariada, permaneceram associados: gênero masculino $(P=0,009) \mathrm{e}$ tabagismo $(P=0,001)$. Conclusão - O presente estudo demonstrou alta prevalência de dependência alcoólica no ambulatório geral de gastroenterologia, estando associada predominantemente ao gênero masculino e ao tabagismo. Ressalta-se que aproximadamente metade dos dependentes não foram identificados como tal na consulta médica, evidenciando a importância da abordagem diagnóstica no paciente alcoolista.

DESCRITORES - Consumo de bebidas alcoólicas. Assistência ambulatorial. Comorbidade. Diagnóstico. Hepatopatias. Estudos prospectivos.

\section{REFERENCES}

1. Almeida LM, Coutinho, ESF. Prevalência de consumo de bebidas alcoólicas e de alcoolismo em uma região metropolitana do Brasil. Rev. Saúde Públ. 1993:21:23-9.

2. Álvarez AMA. Fatores de risco que favorecem a recaída no alcoolismo. J Bras Psiquiatr. 2007;56:188-93.

3. Amaral RA, Malbergier A. Avaliação de instrumento de detecção de problemas relacionados ao uso do álcool (CAGE) entre trabalhadores da Prefeitura do Campus da Universidade de São Paulo (USP) - Campus Capital. Rev Bras Pisquiatr. 2004;26:156-63.

4. Anthony JC, Warner LA, Kessler RC. Comparative epidemiology of dependence on tobacco, alcohol, controlled substances, and inhalants: basic findings from the National Comorbidity survey. Experimental and clinical Psychopharmacology. 1994;3:244-68.

5. Babor TF, Higgins-Biddle JC, Saunders JB, Monteiro, MG. AUDIT: The Alcohol Use Disorders Identification Test: Guidelines for Use in Primary Care. $2^{a}$ ed. Geneva: World Health Organization. Department of Mental Health an Substance Dependence, 2006.

6. Batel PP, Maitre F, Rueff C. Relationship between alcohol and tobacco dependencies among alcoholics who smoke. Addiction. 1995;90:977-80.

7. Becker U, Deis A, Sorensen TI, Gronbaeck M, Borch-Johnsen K, Muller CF, et al. Prediction of risk of liver disease by alcohol intake, sex and age: a prospective population study. Hepatology. 1996;23:1025-9.

8. Blachier M, Leleu H, Peck-Radosavljevic M, Valla DC, Roudot-Thoraval F. The burden of liver disease in Europe: a review of available epidemiological data. J Hepatol. 2013;58:593-608

9. Calabria B, Clifford A, Shakeshaft AP, Conigrave KM, Simpson L, Bliss D, et al. Identifying Aboriginal-specific AUDIT-C and AUDIT-3 cutoff scores for at-risk, high-risk, and likely dependent drinkers using measures of agreement with the 10-item Alcohol Use Disorders Identification Test. Addict Sci Clin Pract. 2014;9(1):17.

10. Chaieb JA, Castellarin C. Associação tabagismo-alcoolismo: introdução às grandes dependências humanas. Rev. Saúde Públ. 1998;32:246-54

11. Cherpitel CJ. Screening for alcohol problems in the emergency room: A rapid alcohol problems screen. Drug and Alcohol Dependence. 1995;40:133-7.

12. Cherpitel CJ. Brief screening instruments for Alcoholism. Alcohol Health \& Research World. 1997;21:348-51.

13. Crabb DW. Pathogenesis of alcoholic liver disease: newer mechanisms of injury Keio J Med. 1999:48:184-8.

14. Edwards G, Marshall EJ, Cook CCH. O Tratamento do Alcoolismo: Um Guia para Profissionais da Saúde. Porto Alegre: Artmed, 2005.

15. Ferreira LN, Bispo Júnior JP, Sales ZN, Casotti CA, Braga Junior ACR. Prevalência e fatores associados ao consumo abusivo e à dependência de álcool. Ciência \& Saúde Coletiva. 2013;18:3409-18.

16. Fligie NB, Pillon SC, Dunn J, et al. The frequency of smoking and problem drinking among general hospital inpatients in Brazil. São Paulo Medical Journal 2000;118:139-43.
17. Figlie NB, Bordin S, Laranjeira R. Aconselhamento em Dependência Química. São Paulo: Roca, 2004

18. Galduróz J, Carlini E. Use of alcohol among the inhabitants of the 107 larges cities in Brazil - 2001. Braz J Med Biol Res. 2007;40:367-75.

19. Guimarães VV, Florindo AA, Stopa SR, César CLG, Barros MBA, Carandina L, Goldbaum M. Consumo abusivo e dependência de álcool em população adulta no Estado de São Paulo, Brasil. Rev Bras Epidemiol. 2010;13:314-25.

20. Laboratório de Epidemiologia e Estatística. Tamanho de amostra para pesquisa em ciências da saúde. [Internet]. [Access 2014 September 9]. Avaliable from: http:// www.lee.dante.br/pesquisa/amostragem/amostra.html

21. Lim SS, Vos T, Flaxman AD, Danaei G, Shibuya K, AdairRohani H, et al. A comparative risk assessment of burden of disease and injury attributable to 67 risk factors and risk factor clusters in 21 regions, 1990-2010: a systematic analysis for the Global Burden of Disease Study 2010. Lancet. 2012;380:2224-60.

22. Lima CT, Freire ACC, Silva APB, Teixeira RM, Farrel M, Prince M. Concurren and Construct Validity of the AUDIT in an Urban Brazilian Sample. Alcohol and Alcoholism. Oxford. 2005;40:584-9.

23. Masur J, Monteiro M. Validation of the CAGE alcoholism screening test in Brazilian Psychiatry inpatient hospital setting. J Biol Res. 1983;16:215-8.

24. Mendez BE. Uma versão Brasileira do AUDIT - Alcohol Use Disorders Identification Test. Universidade Federal de Pelotas, Pelotas, Brazil. 1999.

25. Moreira LB, Fuchs FD, Moraes RS, Bredemeier M, Cardozo S, Fuchs SC, et al. Alcoholic beverage consumption and associated factors in Porto Alegre, a southern Brazilian city: a population-based survey. J Stud Alcohol. 1996;57:253-9.

26. Nader LA, Mattos AA, Bastos GAN. Burden of liver disease in Brazil. Liver Int. 2014;34:844-9.

27. Paz Filho GJ, Sato LJ, Tuleski MJ, Takata SY, Ranzi CCC, Saruhashi SY, Spadon B. Emprego Do Questionário Cage Para Detecção De Transtornos De Uso De Álcool Em Pronto-Socorro. Rev Ass Med Brasil. 2001;47:65-9.

28. Primo NLNP, Stein AT. Prevalência do abuso e da dependência de álcool em Rio Grande (RS): um estudo transversal de base populacional. Rev Psiquiatr. RS. 2004;26:280-6.

29. Rehm J, Mathers C, Popoya S, Thavorncharoensap M, Teerawattananon Y, Patra J. Global burden of disease and injury and economic cost attributable to alcohol use and alcohol-use disorders. The Lancet. 2009;373:2223-33.

30. Rehm J, Allamani A, Vedova RD, Elekes S, Jakubczyk A, Landsmane I, et al General Practitioners Recognizing Alcohol Dependence: A Large Cross-Sectional Study in 6 European Countries. Ann Fam Med. 2015;13:28-32

31. Rosa AA, Gonçalves SC, Stefani SD, Martins SO, Rosa DD, Hunsche A, et al Percepção e registro de abuso de álcool e de doenças relacionadas num hospital geral universitário. Rev Ass Med Brasil. 1998;44:335-9.

32. Sheehan DV, Lecrubier Y, Sheehan KH, Amorim P, Janavs J, Weiller E, et al. The Mini International Neuropsychiatric Interview (MINI.): the development and validation of a structured diagnostic psychiatric interview for DSM-IV and ICD-10. J Clin Psychiatry. 1998;59:22-33. 
33. Teli MR, Day CP, Burt AD, Bennett MK, James OF. Determinants of progression to cirrhosis or fibrosis in pure alcoholic fatty liver. Lancet. 1995;346:987-90.

34. Torruellas C, French SW, Medici V. Diagnosis of alcoholic liver disease. World J Gastroenterol. 2014;20:11684-99.

35. Trimble G, Zheng L, Mishra A, Kalwaney S, Mir HM, Younossi ZM. Mortality associated with alcohol-related liver disease. Aliment Pharmacol Ther. 2013;38:596-602.

36. Turisco JL, Paya R, Figlie NB, Laranjeira R. As pessoas que precisam, procuram tratamento para o alcoolismo? J Bras Psiquiatr. 2000;9:319-22.

37. Vargas D, Oliveira MAF, Araújo E. Prevalência de dependência alcoólica em serviços de atenção primária à saúde de Bebedouro, São Paulo, Brasil. Cad. Saúde Pública. 2009;25:1711-20.
38. Warren KR, Murray MM. Alcoholic liver disease and pancreatitis: global health problems being addressed by the US National Institute on Alcohol Abuse and Alcoholism. J Gastroenterol Hepatol. 2013;28:4-6.

39. White IR, Altmann DR, Nanchahal K. Alcohol consumption and mortality: modeling risks for men and women at differents ages. British Medical Journal. 2002;325:1-7.

40. World Health Organization. Global Status Report on Alcohol. Department of Mental Health and Substance Abuse - Geneva; 2004. [Internet]. [Access 2014 February 19]. Available from: http://www.who.int/substance_abuse/publications/ alcohol/en/index.html. 